\title{
MANAGING THE SOCIOECONOMIC IMPACTS OF EXTREME WEATHER EVENTS IN THE SOUTHWEST PACIFIC BASIN
}

\author{
VIVIENNE SAVERIMUTTU \& MARIA E. VARUA \\ School of Business, Western Sydney University, Sydney.
}

\begin{abstract}
Cyclones are a recurrent feature in the Southwest Pacific basin. Australia, Papua New Guinea, Fiji and New Zealand are responsible for monitoring and forecasting cyclone activity in the region. In dealing with extreme events of this nature, the small islands and atolls have had to depend heavily on their more developed neighbours for assistance. Under the FRANZ and Pacific Island Forum (PIF) arrangements Australia, New Zealand and France have an agreement in place to assist partner countries when such disasters strike. The last category five cyclone (Australian scale), to make landfall in this region was Cyclone Winston, which devastated the Island of Fiji in 2016. Fiji is one of the 16 independent member States of the PIF, which includes Australia and New Zealand. Following the Hyogo Framework for Action 2005-2015, an outcome of the World Conference on Disaster Reduction held in January 2005, the PIF convened a meeting, in Madang, Papua New Guinea, to develop a regional Framework for implementation. Foremost in mind were the social and economic structures of these countries where entire communities could lose their livelihoods or face severe disruption as a result of one disaster. This paper explores disaster management, of the impact of severe cyclones, by these PIF countries (excluding Australia and New Zealand), specifically in terms of disaster prevention, preparedness, relief and recovery. Specific focus will be on the islands of Fiji, Tonga and Vanuatu, where category five cyclones made landfall within the last three years and Samoa, where a category four cyclone made landfall in 2012.
\end{abstract}

Keywords: cyclones, Pacific islands, regional cooperation, socioeconomic impacts and management

\section{INTRODUCTION}

Natural disasters are a persistent characteristic of the Southwest Pacific (SWP) basin. Fourteen member States of the Pacific Island Forum (PIF) located within this region are Small Island Developing States (SIDS). The social and economic structures of these SIDS are incapable of coping effectively with severe natural disasters. Thus, when natural disasters strike, more often than not, these SIDS have had to seek assistance from Australia and New Zealand, their more developed neighbours. Australia and New Zealand are also members of the 16 nation PIF regional partnership.

A study by the World Bank [1], assessing the period between 1950 and 2004, reported that more than 3.4 million people have been affected by natural disasters in the SWP region. Reported fatalities during this period, excluding the more than 2,000 deaths resulting from the 1998 Tsunami that struck the Aitape Province of Papua New Guinea [2], were 1747. There is no doubt that a tsunami would have the most devastating impact in terms of fatalities and infrastructure damage on these fragile nations let alone Australia or New Zealand. Further, as reported by the World Bank [1] drought has affected the most number of people in this region. However, the overwhelming majority of natural hazards reportedly affecting the SWP basin are tropical cyclones (TCs), which had the highest frequency of occurrence during this 50 year period. The most recent category five TC (Australian cyclone category scale), to make landfall in this region at the time of writing this article, was cyclone Winston, which struck the island of Fiji, on the 20th of February 2016 [3]. 
A category 5 TC based on the Australian scale is a severe cyclone accompanied by extremely destructive wind gusts of speeds greater than $280 \mathrm{~km} / \mathrm{h}$, which equates to Beaufort 12. On the Beaufort scale this is the highest category and is classified as a Hurricane [4]. The island economies located in the SWP include a high dependence on tourism, agriculture and fisheries in general. Severe cyclones not only disrupt economic activity, but also result in, damage to essential infrastructure and social sectors, coastal erosion as a result of storm surges, disruption of access to basic needs and because of budgetary and human resource problems a slow recovery. This paper will explore the management of the impact of TCs in the PIF SIDS located in the SWP region. Specific focus will be on the islands of Fiji, Tonga and Vanuatu, countries that have experienced category five cyclones making landfall within the last three years and Samoa, where a category four cyclone was experienced in 2012. Section 2 will assess the impact of cyclones on these SIDS, with particular focus on the productive sector of tourism, followed by an exploration of pre-disaster prevention and preparedness strategies and a post disaster assessment of relief and recovery.

\section{IMPACT, EXPOSURE AND VULNERABILITY}

Although Vanuatu and Fiji, SIDS that are a part of the Melanesian ethno-geographic grouping, experienced higher incidences of cyclones during the period 1950 to 2004, the impact of such events on social and economic structures was considered greater in Samoa and Tonga, SIDS that belong to the Polynesian grouping [1]. The extent of the destruction caused by a cyclone increases as its strength increases. Some authors $[5,6]$ contend that the intensity of cyclones has increased in recent decades as a result of rising sea surface temperature (SST), generating more category 4 and 5 cyclonic events since the 1970s. The events of the last 5 years within the SWP appear to justify this viewpoint.

Samoa experienced a category four cyclone, Evan, in December 2012, which while killing 14 people and displacing 7,500 people or more, damaged and destroyed homes and key infrastructure and disrupted the livelihoods of many [7]. A category five cyclone, Ian, destroyed nearly $11 \%$ of Tonga's GDP in 2014, while affecting approximately 5500 people and damaging or destroying almost $75 \%$ of the Tongan island of Ha'apai's housing stock and other buildings [8]. When a category five cyclone, Pam, struck approximately a third of Vanuatu's islands in 2015, it caused 11 fatalities and affected nearly 188,000 people with 75,000 needing emergency shelter. The total impact was estimated at $64 \%$ of Vanuatu's GDP [9]. In 2016, a category five cyclone, Winston, affected $15 \%$ of Fiji's population, and the damage was estimated at approximately $32 \%$ of GDP with 44 fatalities [10]. The following sub-sections examine the impact of cyclones on the productive, social and infrastructure sectors of these four countries, especially growth rates in the tourism industry, which is of growing importance within the SWP region, followed by their exposure to risk.

\subsection{Impact of cyclones on the tourism industry}

Quarterly time series data on cyclone activity [11] and tourist arrivals by air to Fiji [12], Samoa [13], Tonga [14] and Vanuatu [15] for the years 2002-2016 was gathered for the purpose of analysing the impact of cyclones on tourism, an important industry in terms of employment and economic growth. The augmented Dicky-Fuller tests indicate that the data for both growth rates of tourist arrivals and cyclone activity are stationary, a necessary condition to run simple regression analysis of time series data (Table 1).

Table 2 displays negative correlation coefficients for each country with $\mathrm{p}$ values significant at $1 \%$ for Fiji, Tonga and Vanuatu and $10 \%$ for Samoa confirming that cyclonic activity 
Table 1: ADF (unit root test) Tau statistic.

\begin{tabular}{lllll}
\hline Variable Name & Fiji & Samoa & Tonga & Vanuatu \\
\hline Arrivals- Quarterly growth rate & $-7.533 * * *$ & $-9.508 * * *$ & $-10.265 * * *$ & $-7.334 * * *$ \\
Quarterly data cyclone activity & $-7.628 * * *$ & $-7.843 * * *$ & $-8.236 * * *$ & $-8.665 * * *$ \\
\hline
\end{tabular}

***significant at $1 \%$ level of significance

Table 2: Impact of cyclones on growth rates of tourist arrivals from 2002 to 2016.

Cyclone

\begin{tabular}{lll}
\hline $\begin{array}{l}\text { Variable } \\
\text { Quarterly Growth Rate Arrivals }\end{array}$ & Correlation coefficient & P-value \\
\hline Fiji & -0.37787 & $0.003171^{* * *}$ \\
Samoa & -0.23050653 & $0.090436^{*}$ \\
Tonga & -0.47413 & $0.000149 * * *$ \\
Vanuatu & -0.60806054 & $8.48289 \mathrm{E}-07 * * *$ \\
\hline
\end{tabular}

***,**,* significant at $1 \%, 5 \%$ and $10 \%$ respectively

during the 15 years affected the tourism industry. The correlation coefficient values indicate that Vanuatu experienced the greatest impact. This result is not surprising considering that Vanuatu experiences a higher frequency of cyclones being located at the centre of the Pacific cyclone belt [16].

\subsection{Impact of cyclones on other sectors}

Cyclones have also affected other productive sectors such as agriculture, livestock and fisheries, manufacturing and commerce in Samoa, Tonga and Vanuatu and additionally the mining sector in the case of Fiji. Table 3 below details the total of the estimated damage and loss from all sectors in US dollars. The exchange rate used is the rate prevailing at the time the severe cyclone was experienced by each of the four countries during the years 2012 to 2016. Although three of the countries experienced a category five cyclone, the extent of the damage depended on the cyclone track and the level of development along its path. Thus, comparisons of the estimated monetary value of the impact based on the strength of the cyclone are futile.

Fiji, the most developed and wealthiest of the four countries, sustained the highest level of damage, estimated at US\$ 1.3 billion, when cyclone Winston made landfall on the largest island, Viti Levu, followed by storm surges affecting the second largest island, Vanua Levu, with the entire island losing power [17]. In Vanuatu, the worst impacts of cyclone Pam were felt on the larger islands Efate, Tanna and Erromango. However, estimates of the total of damage and loss are based on the best available information and therefore incomplete [16]. The impact of cyclone Evan on Samoa was significant considering the relatively small size of the Samoan economy. Major damage was sustained in Apia and the central agricultural areas of Upolu [18]. The damage caused by cyclone Ian occurred as it passed directly over the northeast islands of Ha'apai in Tonga. The information on damage and loss resulting from cyclone Ian is also incomplete [19, 20]. 
Table 3: Damage and loss caused by cyclones in the SWP 2012-2016.

\begin{tabular}{|c|c|c|c|c|}
\hline Sectors & $\begin{array}{l}\text { Fiji } 2016 \\
\text { US\$ Millions } \\
{[17]}\end{array}$ & $\begin{array}{l}\text { Samoa } \\
2012 \text { US\$ } \\
\text { Millions } \\
{[18]}\end{array}$ & $\begin{array}{l}\text { Tonga } 2014 \\
\text { US\$ millions } \\
{[19-20]}\end{array}$ & $\begin{array}{l}\text { Vanuatu } 2015 \\
\text { US\$ millions } \\
{[16]}\end{array}$ \\
\hline \multicolumn{5}{|l|}{ Productive Sectors } \\
\hline Agriculture, livestock, fisheries & 254.46 & 32.80 & 20.8 & 57.74 \\
\hline Manufacture \& commerce & 67.04 & 17.12 & N/A & 31.89 \\
\hline Tourism & 56.34 & 21.89 & 0.86 & 90.65 \\
\hline Mining & 14.79 & - & - & - \\
\hline \multicolumn{5}{|l|}{ Social Sectors } \\
\hline $\begin{array}{l}\text { Education, health, housing } \\
\text { Infrastructure Sectors }\end{array}$ & 407.46 & 24.89 & 27.42 & 142.57 \\
\hline $\begin{array}{l}\text { Electricity, transport, water \& } \\
\text { sanitation, } \\
\text { Cross-sector }\end{array}$ & 116.71 & 75.43 & 8.92 & 88.86 \\
\hline Environment & 422.39 & 31.86 & N/A & 50.75 \\
\hline Total & $1,339.19$ & 203.99 & 58.0 & 462.46 \\
\hline
\end{tabular}

\subsection{Hazard risk, exposure and vulnerability}

Despite increasing research on the frequency of TCs, no trend has been identified other than increasing destructiveness relating to greater intensities of the TCs [5]. The risks associated with TCs are based on clear-cut aspects of hazard, exposure and vulnerability with consequences relating to different timeframes. The immediate problems to be dealt with are damage, mortality, morbidity, displacement and asset damage. The hazard arising from TCs relate to storm surges and floods resulting from strong winds and torrential rainfall. In the SWP, with increasing development in coastal areas and subsequent increases in population densities, the exposure to risk from TCs is growing [21]. Further, the vulnerability of coastal populations is higher due to storm surges. Populations living in remote rural areas are also more vulnerable to risk, though in urban areas slum dwellers appear to be more at risk in comparison with urban residents living in better constructed dwellings [22].

\subsection{Socioeconomic profiles of the SIDS}

Vanuatu heads the World Risk Index [23], for both exposure and vulnerability to natural hazards, followed by Tonga. Fiji is 16th on the list and Samoa is not listed in 2015 (51st in 2012). In Vanuatu, although it is difficult to identify instances of extreme poverty, the remoteness of some rural areas and lack of access to basic infrastructure, exacerbated by budgetary problems of the government, reduces connectivity [16] creating problems for effective pre-disaster management. Figures 1 and 2 below [24] display access to electricity by the rural and urban populations of the four SIDS. Vanuatu has only $12.7 \%$ of the population living below the poverty line. Yet, access to electricity is lowest in Vanuatu reflecting the remoteness of the rural community and a GDP per capita, which is below the Pacific average. 


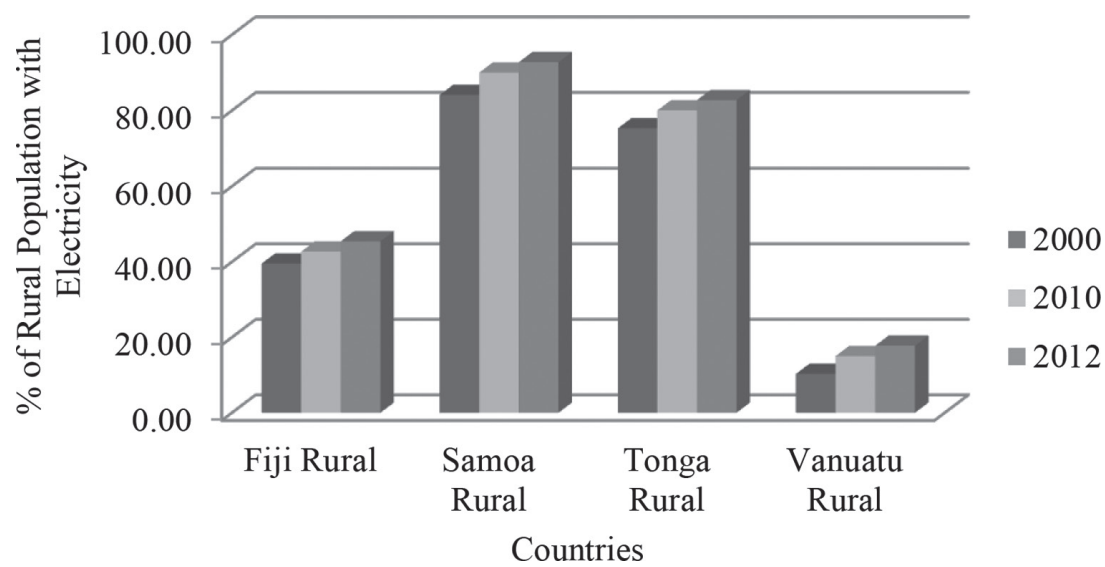

Figure 1: Access to Electricity - Rural Population

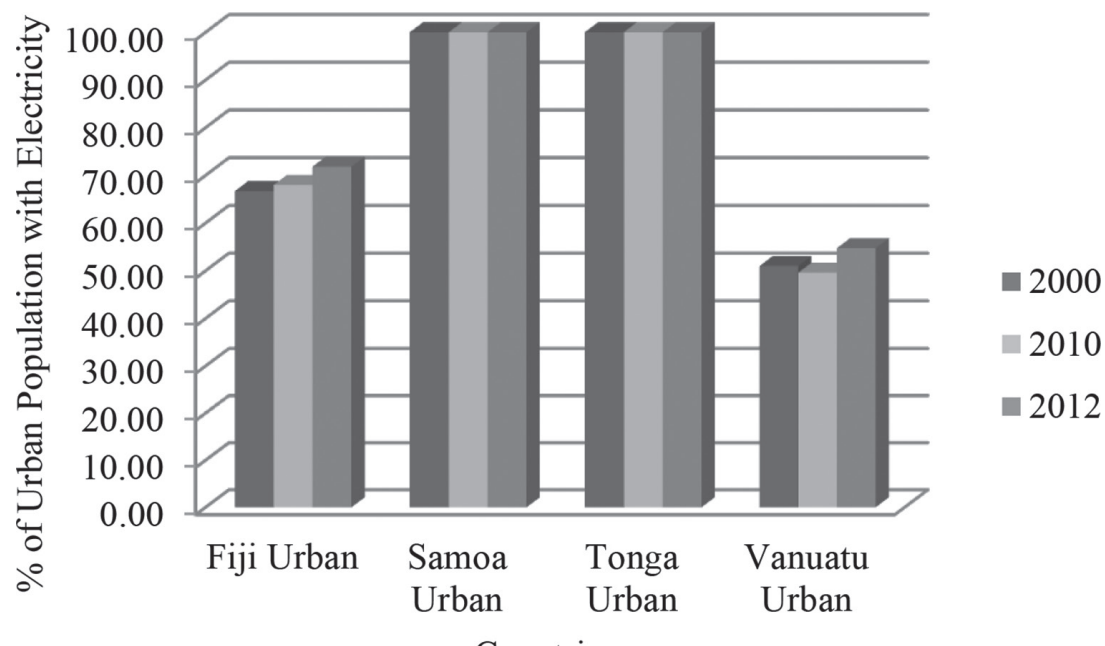

Countries

Figure 2: Access to Electricity - Urban Population

Despite being a relatively wealthier country, the data for Fiji too reflects the remoteness of some islands and also the relatively high percentage (35\%) of the total (44\% rural and $26 \%$ urban) population living below the poverty line. Samoa and Tonga have $26.9 \%$ and $22.5 \%$, respectively, of the population existing below the poverty line [25]. However, they have policies in place that have ensured high access to electricity by the rural and urban populations of both countries. In Samoa, nearly $77 \%$ of residential electricity usage is accessed on a prepayments basis. In Tonga, the government has concentrated on energy efficiency and least cost access [26].

\section{PREVENTION, PREPAREDNESS, RELIEF AND RECOVERY}

A cyclone cannot be prevented, but its impact can be managed such that the affected communities can cope with its worst effects when it strikes, minimise the losses in the medium term 
and recover in the long term without a permanent loss in wellbeing. Therefore, prevention is discussed in terms of pre-disaster monitoring and forecasting activities resulting in timely warnings, regarding the cyclone's category and track, facilitating the possibility of better preparedness. The SWP region has dealt with cyclones over centuries. To some extent, the oral transmission of traditions by the indigenous population has resulted in some knowledge of coping strategies surviving through to present times. Such knowledge though useful may be inadequate because of changes in climate due to global warming and changes in frequency of occurrence and intensity of the TCs along with increased levels of development. Also much knowledge has been lost due to the introduction of modern methods and further traditional knowledge has not been enhanced following improvements and advances in science and technology.

The emphasis here is on being better prepared utilising both indigenous coping strategies and modern methods ensuring that the impact of the worst cyclone does not exceed the capacity of the affected community to cope. Currently though, this is an aspiration for countries in the SWP, including the SIDS that are the focus of this study, due to their, in some cases, excessive, dependence on the international community for assistance with pre-disaster monitoring and forecasting as a preventive strategy and preparedness as well as for post-disaster relief and recovery.

\subsection{Monitoring and forecasting as a preventive strategy}

The World Meteorological Organisation (WMO), under its World Weather Watch Programme [27], has established a Regional Specialised Meteorological Centre (RSMC) in Nadi, Fiji. This is one of six RSMCs established around the globe to monitor cyclone activity and provide warnings and advisories to countries within its area of responsibility. The area of responsibility of the RSMC-Nadi Tropical Cyclone Centre (160E to 120W, Equator to 25S) includes, Samoa, Tonga and Vanuatu. In close proximity are Tropical Cyclone Warning Centres (TCWCs) established in, Port Moresby, Papua New Guinea, Brisbane, Australia and Wellington, New Zealand.

Australia and New Zealand, as PIF members, are responsible for regional security and therefore monitor cyclone activity in the SWP area ensuring that other member countries are able to maintain the stability of their economies. An event categorised as a disaster, signifies that the impact of the event exceeds the capability of the affected SIDS to cope.

Additionally, there are National Meteorological Services in Samoa and Vanuatu. In the event of a cyclone, timely information fed effectively into the Early Warning Systems (EWS) is essential so that preparation to meet the threat could get underway speedily. However, there are problems with the EWSs in place. In Samoa, it was reported that only the Joint Typhoon Warning Centre (JTWC) located in the US, which also issues cyclone warnings for the SWP, correctly predicted the track for cyclone Evan in 2012. Communication to the public was also not timely due to procedural delays at the RSMC in naming the cyclone pointing to human resource constraints [18]. The post-disaster assessment on cyclone Pam raised concerns on the lack of a reliable scientific basis underlying the prediction and forecasting of cyclones [16] in 2014. In communicating the information to the public in Vanuatu, the use of social media, radio and mobile phones was critical as in Fiji when preparing for cyclone Winston in 2016 [17]. Figure 3 below details the increase in mobile phone usage in the four SIDS since 1998.

However, if a cyclone damages the communications systems, as it did in Vanuatu, then remote rural communities as well as urban communities can experience reduced connectivity in the post disaster relief period. 


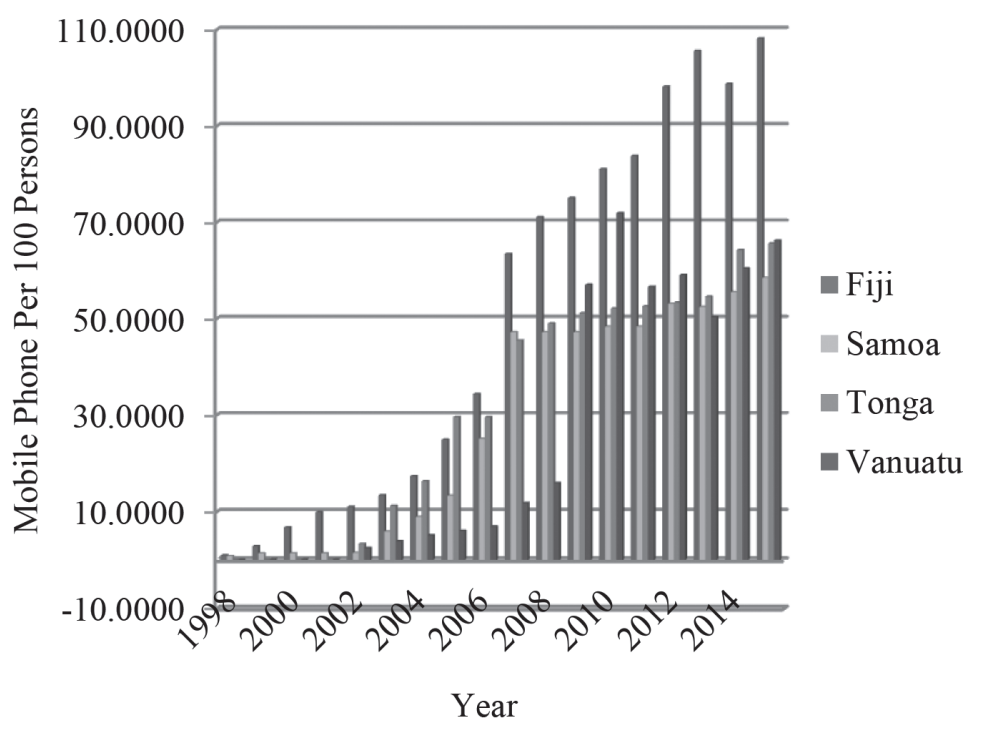

Figure 3: Increase in mobile phone usage per 100 persons 1998-2015.

\subsection{Preparedness}

Samoa, having experienced a tsunami in 2009, had disaster response plans in place. However, it was reported that at community level, preparedness was generally low even though most people felt that they had a good understanding of cyclones having experienced it before. This community sentiment was probably due to the fact that the cyclone warning was not timely for reasons stated previously. Further, officially designated evacuation centres were operational for the first time but only in urban areas. Overall, a need was expressed for a multi-hazard, community level, disaster management plan to address the preparedness gaps that were experienced [18]. In Tonga, the Meteorological Service was praised by communities for timely alerts on the impending cyclone Ian. Warnings continued even after the cyclone had moved on to Fijian waters. However, a need for improving community response was expressed, as feedback indicated that many residents accessed the evacuation centres only after they had been exposed to danger [28].

The Vanuatu Meteorological and Geo-hazards Department (VMGD) was effective in alerting the public of the approaching hazard, cyclone Pam, in a timely and accurate manner. This fact and the response of the public to the warnings to seek appropriate shelter, is credited with having limited the loss of life to 11 persons. There were no cyclone proof emergency shelters in Vanuatu. So public buildings, which had not been purpose built to withstand category 5 cyclones, were used as emergency shelters. A cyclone with devastation to such an extent occurred nearly 30 years prior to cyclone Pam. Therefore, the residents were inexperienced in taking steps to minimise damage to property. The needs of vulnerable members of society too were not taken into consideration [16]. In Fiji, disaster risk management was considered proactive having evolved significantly over the past three decades. There was effective transmission of monitoring data to accurately predict the cyclone's path and issue timely and accurate warnings on what needed to be done in preparation. However, here too, inexperience of storms of such intensity resulted in poorly located evacuation centres [17]. 


\subsection{Relief}

In the event of an extreme weather event or any other disaster the four countries are dependent on the international community for assistance, not only to fund relief operations but also for logistical support and human resource skills. Under the FRANZ arrangement signed in December 1992, three countries, France, Australia and New Zealand, stand ready, if requested, to provide aerial reconnaissance and co-ordinate relief assistance working with national counterparts in their 12 partner countries within the SWP. This arrangement recognises the vulnerability of these Pacific island SIDS when a disastrous event occurs, which often exceeds the capacity of the country to cope with on its own. All four SIDS, which are the focus of this study, requested assistance during the period 2012 to 2016.

Following cyclone Evan, an assistance team with essential equipment was sent by France, while Australia and New Zealand assisted with relief supplies. In response to cyclone Ian, relief supplies from New Zealand were flown to Tongatapu. A smaller plane (CASA) supplied by France was used to transport these relief supplies, as well as supplies stockpiled by Australia in Tongatapu (held by the Tongan Red Cross), to Ha'apai. The CASA is a useful smaller plane, which can easily land and take off on shorter tracks [29]. Relief assistance following cyclone Pam included aerial reconnaissance to assess the damage as well as cargo flights transporting humanitarian assistance teams and supplies under the FRANZ partnership [30].

Similar assistance was offered to Fiji following cyclone Winston. France supplied a CASA to transport supplies and humanitarian work teams, and a helicopter to Fijian authorities for aerial reconnaissance and transport of medical equipment [31]. Australia despatched HMAS Canberra carrying defence force personnel, emergency medical supplies, food and water [3]. Both Fiji and Vanuatu have remote areas that were affected and required additional support. New Zealand too assisted with aerial reconnaissance.

Assistance in terms of emergency supplies and support personnel, for all four SIDS, were also provided by the PIF SIDS that were not affected, International Organisations and various NGOs. Most importantly, financial assistance was supplied in the form of grants from various countries and international organisations, including the World Bank. The governments of the affected countries too approved tax concessions and drew from their own funds set aside for disaster relief efforts. Such funding was required not only for short term relief efforts but also the medium term and longer term recovery plans.

\subsection{Recovery}

The first priority, in terms of relief efforts, was to restore communications and electricity, clean up debris to secure access to airports and affected areas and ensure food supplies, water, sanitation and hygiene products (WASH), shelter and protection for those affected. Social structures, relating to education and health, that had sustained damage, also required attention with temporary structures set in place with as little delay as possible. In each case a state of emergency was declared by the Prime Minister of the affected country. While processes to attend to these immediate term needs were underway, post disaster needs assessments (PDNA) were being prepared to seek much needed funds and plan the management of the medium term and long term recovery. The damage and loss sustained for which funding was required has been illustrated in Table 3 under section 2.2.

In Samoa long term recovery projects focussed on strengthening resilience by constructing weather resistant roads and relocating people away from the coast line (Enhanced road access 
project), improving response to disasters through the Agriculture and fisheries cyclone response project, and, improving financial management of future shocks through the Samoa development policy operations project [7]. In Tonga's Ha'apai islands, the Tonga cyclone reconstruction and climate resilient project focussed on improving housing resilience through safe home construction and providing new technology for housing damage assessments [8]. Projects are also under way to make electricity and transport infrastructure more resilient to cyclone damage. In Vanuatu, extensive infrastructure rehabilitation work, including an improved EWS has received attention for long-term funding [9]. In Fiji [32], the rural areas were the worst hit. As such, long-term recovery needs include financial support for vulnerable communities through its social protection system as well as those needs identified in the PDNA (Table 3, Section 2.2).

\section{CONCLUSION AND RECOMMENDATIONS}

The management of the impact of severe cyclones during the past 5 years, in four SIDS located in the SWP, was examined in terms of pre-disaster monitoring and forecasting (prevention) and preparedness followed by post disaster relief and recovery assessments. Each of these SIDS experienced a severe cyclone within the last five years. In each case, managing the socioeconomic impacts, of these extreme weather events, required the assistance of Australia and New Zealand in particular, as well as other countries and international organisations. Some lessons learned and recommendations based on good practice in managing these events are elucidated below.

As a preventive measure effective monitoring and forecasting is essential. In Vanuatu, the EWS was damaged and a recommendation was made to protect the EWS infrastructure and ensure sound monitoring and forecasting based on scientific methods [16]. Delays experienced in Samoa emphasise the need for timeliness of warnings, which will ensure better preparation in securing assets that could sustain damage. In the pre-disaster period, it is important to ensure that a mix of indigenous and modern methods prevail to achieve the best results. For example the cultivation of cyclone resistant foods based on indigenous traditions while utilising modern cyclone resistant storage facilities for food and water. Considering that loss of communication and power was an issue in all cases, it is essential to ensure that alternatives are in place, when preparing for the disaster, to fall back on in the post disaster period. Although mobile, phones and high frequency (HF) radios proved to be useful communication tools, both the HF antennae and cellular towers were damaged in Vanuatu and communication had to be conducted via internet. For power shortages and disruptions, solar lanterns are a cheap and durable alternative as a lighting source, especially for the rural poor, when power lines are damaged. As cyclones are a seasonal occurrence in this region, clearing and securing potential sources of debris and damage to essential infrastructure prior to the cyclone season is an option. Also as highlighted by Samoa in its PDNA, a community level disaster management plan would ensure timely evacuation, which was not the case for many in Tonga in 2013.

Budgetary and human resource constraints and the extent of generally unplanned development in these SIDS, impose severe restrictions in terms of coping with disastrous events without international assistance for relief and recovery. Additionally, Fiji and Vanuatu face the problem of remoteness and difficulty of access to some of their rural areas. Budgetary and human resource constraints faced by these SIDS are unlikely to change in the near future and recovery will be slow. Most of the projects that commenced as a response to a severe cyclone, as early as in 2013, have had their original end dates extended to 2017 . What can be done is to ensure that funds released for recovery be utilised to address the human resource 
constraints as well as the financial management skills of local disaster management offices in addition to reconstruction and recovery. Further, the problem of coastal development could also be addressed. Relocation of some communities from coastal areas has already commenced in some SIDS. Traditionally, the indigenous population would relocate to higher ground following a severe cyclone.

Finally, the projects that focus on cyclone resilient durable infrastructure, implicitly acknowledge that the impact of climate change is serious. Funding will most certainly be inadequate to ensure that future damage will be minimal. Perhaps, an alternative would be to consider the use of Pacific architecture [33] like the fale (house) in Samoa, a fabrication that will be damaged by cyclones but replaceable easily and cheaply and could be managed to fall within the budgetary capabilities of the SIDS.

\section{REFERENCES}

[1] World Bank. Not if but when. Adapting to natural hazards in the Pacific Islands region: A policy note, 2006. Available at: http://documents.worldbank.org/curated/ en/2006/01/6589273/not-adapting-natural-hazards-pacific-islands-region-policy-note. (accessed 15 April 2017).

[2] Geoscience Australia. The Aitape Papua New Guinea Earthquake and Tsunami, 1998. Available at: https://data.gov.au/dataset/the-aitape-papua-new-guinea-earthquake-andtsunami-1998. (accessed 15 April 2017).

[3] DFAT Australia. Tropical cyclone Winston, Available at: http://dfat.gov.au/aid/topics/ investment-priorities/building-resilience/humanitarian-preparedness-and-response/tcwinston/Pages/default.aspx. (accessed 16 April 2017).

[4] Bureau of Meteorology Australia. Tropical cyclone intensity impacts. Available at: http://www.bom.gov.au/cyclone/about/intensity.shtml. (accessed 15 April 2017).

[5] Emanuel, K.A., Increasing destructiveness of tropical cyclones over the past 30 years. Nature, 436(7051), pp. 686-688, 2005.

https://doi.org/10.1038/nature03906

[6] Webster, P.J., Holland, G.J., Curry, J.A. \& Chang, H.-R. Changes in tropical cyclone number, duration and intensity in a warming environment. Science, New Series, 309(5742), pp. 1844-1846, 2005.

https://doi.org/10.1126/science.1116448

[7] World Bank. Resilient recovery in Samoa after cyclone Evan, 2014. Available at: http:// www.worldbank.org/en/results/2014/09/08/resilient-recovery-samoa-after-cycloneevan. (accessed 18 April 2017).

[8] World Bank. Building back better in Tonga after cyclone Ian, 2014. Available at: http:// www.worldbank.org/en/results/2014/10/01/building-back-better-tonga-cyclone-ian. (accessed 18 April 2017).

[9] World Bank. Supporting resilient recovery in Vanuatu after cyclone Pam, 2016. Available at: http://documents.worldbank.org/curated/en/906741468196132305/ pdf/103269-BRI-Vanuatu-Box394863B-PUBLIC-ADD-SERIES-Stories-of-impact. pdf. (accessed 8 April 2017).

[10] World bank. World Bank commits $\$ 50$ million to support Fiji's long-term cyclone Winston recovery, 2016. Available at: http://www.worldbank.org/en/news/pressrelease/2016/06/30/world-bank-commits-50m-to-support-fijis-long-term-cyclonewinston-recovery. (accessed 18 April 2017). 
[11] Australian Severe Weather. Available at: http://www.australiasevereweather.com/ cyclones/summary_jtwc.htm. (accessed 7 April 2017).

[12] Reserve Bank of Fiji. Available at: http://www.rbf.gov.fj/. (accessed 4 April 2017).

[13] Central Bank of Samoa. Available at: http://www.cbs.gov.ws/. (accessed 4 April 2017).

[14] Tonga department of Statistics. Available at: http://tonga.prism.spc.int/social/migration-statistics. (accessed 7 April 2017).

[15] Vanuatu National Statistical Office. Available at: http://www.vnso.gov.vu/. (accessed 20 March 2017).

[16] World Bank. Vanuatu: Post-disaster needs assessment, tropical cyclone Pam, March 2015. Available at: http://dfat.gov.au/about-us/publications/Documents/post-disasterneeds-assessment-cyclone-pam.pdf. (accessed 16 April 2017).

[17] World Bank. Fiji: Post-disaster needs assessment, tropical cyclone Winston, 2016, Available at: https://www.gfdrr.org/sites/default/files/publication/PostDisasterNeedsAs sessmentsCYCLONEWINSTONFiji2016(Online\%20Version).pdf. (accessed 16 April 2017).

[18] World Bank. Samoa: Post-disaster needs assessment, tropical cyclone Evan, 2012. Available at: http://www.gfdrr.org/sites/gfdrr/files/SAMOA_PDNA_Cyclone_ Evan_2012.pdf. (accessed 16 April 2017).

[19] FAO, Tonga. Cyclone Ian in Ha'apai: Rapid damage assessment to the agriculture and fisheries sectors report, 2014. Available at: http://reliefweb.int/report/tonga/cycloneian-ha-apai-rapid-damage-assessment-agriculture-and-fisheries-sectors-report. (accessed 16 April 2017).

[20] National Emergency Operations Committee. Tonga, Tropical cyclone Ian response plan 30 January 2014. Available at: http://reliefweb.int/report/tonga/tropical-cyclone-ianresponse-plan. (accessed 16 April 2017).

[21] Noy, I., The socio-economics of cyclones. Nature Climate Change, 6, pp. 343-348, 2016. Available at: www.nature.com/natureclimatechange. (Accessed 17 April 2017). https://doi.org/10.1038/nclimate2975

[22] Peduzzi, P., Chatenoux, B., Dao, H., De Bono, A., Herold, C., Kossin, J., Mouton, F. \& Nordbeck, J., Global trends in tropical cyclone risk. Nature Climate Change, 2, pp. 289-294, 2012. Available at: www.nature.com/natureclimatechange. (accessed 17 April 2017). https://doi.org/10.1038/nclimate1410

[23] UNU-EHS. World risk report, 2015, Available at: www.WorldRiskReport.org. (accessed 20 April 2017).

[24] World Development Indicators. Available at: http://databank.worldbank.org/data/ reports.aspx? source=world-development-indicators. (accessed 23 March 2017).

[25] ADB. Poverty in Samoa, share of population below the poverty line. Available at: https://www.adb.org/countries/samoa/poverty. (accessed 20 April 2017).

[26] Promoting energy efficiency in the Pacific - phase 2. Available at: http://www.ee-pacific.net/ index.php/database/country-information/. (accessed 20 April 2017).

[27] WMO. Available at: http://www.wmo.int/pages/prog/www/tcp/Advisories-RSMCs. html. (accessed 20 April 2017).

[28] SPREP. Lessons learnt by Tonga Met Service after cyclone Ian. Available at: http:// www.sprep.org/climate-change/lessons-learnt-by-tonga-met-service-after-cyclone-ian. (accessed 23 April 2017). 
[29] The FRANZ arrangement. Available at: https://www.mfat.govt.nz/assets/_securedfiles/AidProg-docs/NZDRP-docs/Franz-Arrangement-Brochure.pdf. (accessed 23 April 2017).

[30] UNICEF. Cyclone Pam situation report No: 3. Available at: https://www.unicef.org/ pacificislands/Cyclone_Pam_SitRep_3.pdf. (accessed 25 April 2017).

[31] French help after the passage of cyclone Winston. Available at: https://fj.ambafrance. org/French-Help-after-the-passage-of-cyclone-Winston-February-24-2016. (accessed 25th April 2017).

[32] World Bank. World Bank commits $\$ 50$ million to support Fiji's long-term cyclone Winston recovery. Available at: http://www.worldbank.org/en/news/press-release/2016/06/30/ world-bank-commits-50m-to-support-fijis-long-term-cyclone-winston-recovery. (accessed 25 April 2017).

[33] Mckay, B., Maori architecture: transforming western notions of architecture. Fabrications, 14(1\&2), pp. 1-12, 2004.

https://doi.org/10.1080/10331867.2004.10525189 